\title{
Doença de Ménière em criança
}

\section{Ménière's disease in children}

\author{
Gustavo J. Magalhães ${ }^{1}$, Gustavo G. Pacheco ${ }^{1}$
}

\section{Resumo / Summary}

\begin{abstract}
$\mathbf{A}$
Doença de Ménière foi descrita pela primeira vez por Prosper Ménière no século XIX e ainda nos dias atuais não existem explicações definitivas para a sua etiologia e para a sua fisiopatologia. A tétrade formada por esta doença é constituída de zumbido, vertigem, queda da acuidade auditiva e a sensação de plenitude aural. A faixa etária mais acometida pela doneça de Méniére corresponde à terceira e quinta décadas de vida, sendo de ocorrência pouco comum em crianças. Este relato tem como objetivo demonstrar que a doença de Ménière, mesmo sendo de baixa ocorrência em crianças, pode vir a acometer esta população e o otorrinolaringologista deve estar apto para o diagnóstico e tratamento. Neste relato de caso, uma criança de 11 anos apresentou, após um episódio de edema facial de causa indeterminada associado a sintomas cócleo-vestibilares, um quadro de Doença de Ménière após uma investigação mais minuciosa. O tratamento com drogas depressoras do labirinto e vasodilatadoras promoveram uma melhora sensível, dando fim à sintomatologia.
\end{abstract}

Palavras-chave: vertigem, doença de Ménière, tratamento. Key words: vertigo, Ménière's disease, treatment.

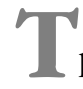

he Ménière's Disease was described at first time by Prosper Ménière in XIX century and nowadays continues without explications for the etiology and fisiopatology. The disease has four symptoms that are correspond to: tinnitus, vertigo, hearing loss and aural fullness. The ages that this disease is most frequent are the third and the five decades of live and the occurrence in children is rare. This article want to show to the otorhinolaryngologists the existence of the Ménière's disease in child and the conduction of the case. In this case report a child with 11 years old presented as initial manifestation a facial edema and several cocleo-vestibular symptoms that was studied and confirm the diagnosis of Ménière's Disease. The treatment with labirintic depressive drugs promotes a good response.

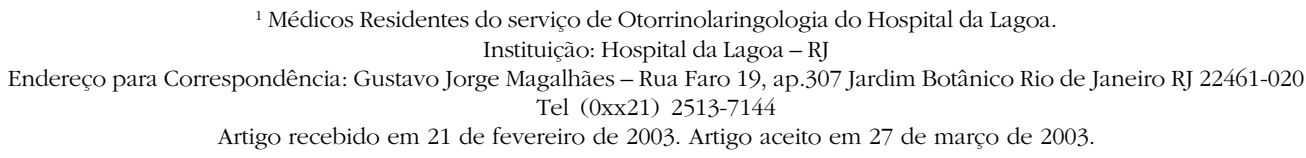




\section{INTRODUÇÃO}

A vertigem é um dos mais complicados sintomas para o médico e para o paciente, pois este apresenta dificuldades para descrever seus sintomas ${ }^{1}$.

A Academia Americana de Otorrinolaringologia e Cirurgia de Cabeça e Pescoço define como critério diagnóstico de Doença de Ménière dois ou mais episódios de vertigem com duração igual ou superior a 20 minutos; uma perda auditiva documentada pelo menos uma vez e a presença de tinitus e plenitude auricular ${ }^{2}$.

A etiologia da Doença de Ménière é desconhecida e a resposta autoimune é sugerida como a possível patogênese da doença, podendo ocorrer uma perda auditiva nurosensorial súbita como ocorre na síndrome de Cogan e na Doença de Ménière $^{2-4}$.

O exame histopatológico é caracterizado pela hidrópsia endolinfática com distenção e distorção das estruturas do labirinto menbranoso produzida pela endolinfa ${ }^{2,5}$.

A redução da absorção da endolinfa no saco endolinfático e/ou excesso de produção de endolinfa ou mesmo de proteínas osmoticamente ativas pelo saco endolinfático podem ser a gênese desta doença ${ }^{2}$.

Charles Frazier, em 1908, foi o primeiro a curar a vertigem da Doença de Ménière através da secção do oitavo par craniano ${ }^{4}$ e geralmente o diagnóstico é suspeitado pela história e confirmado por exames complementares ${ }^{1,2}$.

\section{REVISÃO}

A Doença de Ménière foi descrita pela primeira vez por Prosper Ménière em 1861 e ainda não temos explicações definitivas tanto para a sua etiologia quanto para a sua fisiopatologia .

A doença pode se manifestar por sintomas cócleovestibulares, só vestibulares ou só cocleares e as afecções responsáveis podem ou não ser conhecidas. Entre as causas mais conhecidas temos: alergia, lues, diabetes e trauma. O agente causador pode ser identificado em torno de 50\% dos casos $^{6}$.

No ano de 1938, Cirus \& Halpike descreveram a hidrópsia como sendo um aumento da endolinfa com a dilatação do labirinto menbranoso devido aumento da produção ou diminuição da absorção ${ }^{2,4,6}$.

Anticorpos anti-HSP70 foram identificados em soro de pacientes com Doença de Ménière. Estes anticorpos foram encontrados em 33,3\% em casos unilaterais e 58,8\% em casos bilaterais e reforçariam a hipótese de doença autoimune, mas são de pouca eficácia clínica para diagnóstico ${ }^{2}$. A reação alérgica tipo III altera a morfologia e a eletrofisiologia auricular semelhantes a desencadeada na Doença de Ménière ${ }^{1}$.

A doença acomete mais a terceira e a quinta década de vida, sendo de ocorrência rara em crianças.
Mizukoshi et al., em revisão de 7418 casos de doença de Ménière de 1979 a 1999, obteve uma incidência de $1,5 \%$ de casos em crianças ${ }^{7}$ sendo que seu compatriota Akagi et al. obteve valores mais elevados em seu estudo, demonstrando uma incidência de 2,9\% do total de pacientes com vertigem ${ }^{8}$.

Numa crise típica de Ménière encontramos: vertigens rotatórias, queda de audição (em geral unilateral), zumbidos, pressão aural, desconforto a sons intensos e sintomas neurovegetativos. As crises podem durar alguns minutos ou horas. Nas intercrises ocorre melhora dos sintomas, inclusive da audição e dos zumbidos; os intervalos podem durar anos ou meses e se tornam mais próximos à medida que a doença evolui.

As crises acometem inicialmente os sons graves e depois acometem os agudos. Após algumas crises, todas as freqüências são acometidas e a perda torna-se irreversível, podendo ser identificada na audiometria tonal limiars.

A ocorrência de crises com flutuação da audição caracteriza a doença de Ménière. O diagnóstico é feito pela história e confirmado pelos exames complementares ${ }^{6}$. A alteração audiométrica já foi relatada e os testes supraliminares determinam recrutamento de Metz e ausência de reflexo estapédico em uma disacusia de conduçãó .

No teste do glicerol, o paciente ingere o agente desidratante e ocorre o conseqüente incremento na audição confirmado pela audiometria limiar tonal ${ }^{2,6}$.

A audiometria do tronco cerebral demonstra uma diferença das ondas I e V, semelhante ao BERA normal. A eletrococlografia pode indicar a hidrópsia constituindo de um bom exame. Uma pobreza de dados pode existir caso o exame seja realizado fora da crise ${ }^{6}$.

O tratamento pode ser clínico ou cirúrgico. O tratamento clínico pode ser feito na fase da crise ou no período intercrise $^{1,6,8}$. Na crise, são utilizados depressores labirínticos como difenidol, dimenidrinato, vitamina B6, associados a outras drogas como os diazepínicos, diuréticos e vasodilatadores. Recomenda-se repouso no leito, refeições leves e abstenção de fumo, café e outros estimulantes labirínticos. No período intercrise são administrados sedativos labirínticos por longos períodos ${ }^{6}$.

A indicação cirúrgica se torna real quando o tratamento clínico não é satisfatório. Existem dois tipos gerais de procedimentos cirúrgicos: conservadores e ablativos. Os procedimentos conservadores constituem-se na cirurgia do saco endolinfático e a cocleosaculotomia. Os procedimentos ablativos incluem a labirintectomia, a secção do nervo vestibular, perfusão labiríntica com estreptomicina ou mesmo a instilação no ouvido médio de gentamicina ou estreptomicina?.

O diagnóstico diferencial com neurinoma do acústico deve sempre ser aventado além de neuronite vestibular, vertigem posicional paroxística benigna e síndrome de Lermoyez . 


\section{APRESENTAÇÃO DO CASO CLÍNICO}

I. J. M., com 11 anos de idade, do sexo masculino, natural de Queimadas - PB e procedente de Campina Grande - PB, compareceu ao Serviço de Otorrrinolaringologia do Hospital da Lagoa - RJ, com a queixa de zumbido intenso, vertigem de aparecimento súbito, queda na acuidade auditiva sempre em ouvido direito, tendo início em novembro de 2001.

Os sintomas surgiram após um episódio de edema facial de aparecimento súbito que foi conduzido ainda no estado da Paraíba onde se aventou a hipótese diagnóstica de insuficiência renal aguda (IRA). Entretanto, EAS realizado durante a fase de edema facial ainda naquela localidade demonstrou parâmetros laboratoriais normais, assim como hemograma, uréia e creatinina. Em ultrassonografia abdominal realizada nesta mesma ocasião os rins eram tópicos e de volume normal descartando definitivamente a hipótese de IRA ou síndrome nefrótica.

Após o início do quadro clínico em Novembro de 2001, o paciente apresentou episódios de crise que se intensificaram, com vertigem rotatória intensa, manifestações vagais, zumbidos, plenitude auricular na crise e redução da acuidade auditiva em ouvido direito após cada nova crise.

Para início da investigação foi solicitado inicialmente uma audiomeria tonal e vocal, além de uma impedanciometria. A audiometria demonstrou uma queda nos limiares tonais em ouvido direito com hipoacusia mista, variando de moderada a grave acometendo todas as freqüências e se intensificando nas graves. A impedanciometria demonstrou ausência de reflexo estapédico nas freqüências de $1000 \mathrm{~Hz}, 2000 \mathrm{~Hz}$ e $4000 \mathrm{~Hz}$.

No BERA foi verificado ausência de onda I em ouvido direito e latências normais das ondas III e V, altamente sugestivo de lesão coclear.

A vectoeletronistagmografia demonstrou estar dentro dos padrões de normalidade em razão do paciente estar fora de crise na sua execução.

Para maiores esclarecimentos a respeito da IRA foi solicitado exames de uréia, creatinina e glicemia de jejum que se apresentaram dentro da normalidade.

Para confirmação da Doença de Ménière foi realizado o teste do glicerol, onde se verificou a melhora de $15 \mathrm{~dB}$ na freqüência de $1000 \mathrm{~Hz}$ e de $10 \mathrm{~dB}$ nas freqüências de $500 \mathrm{e}$ $2000 \mathrm{~Hz}$, confirmando a hipótese diagnóstica de Doença de Ménière.

Para a realização de um diagnóstico diferencial com neurinoma e alterações congênitas que acometem o ouvido interno foi solicitada tomografia computadorizada que determinou normalidade estrutural de ouvido interno e meato acústico interno.

Uma vez estabelecido o diagnóstico, o paciente iniciou o usos de dimenidrinato em associação com vitamina B6 e cinarizina, já que apresentara uma nova crise após o fim da investigação. Após o uso de uma semana do dimenidrinato em associação com vitamina B6, estes foram suspensos e se manteve a cinarizina, quando o paciente apresentou uma supressão das crises e estabilização do quadro clínico e do padrão audiométrico em nova audiometria.

\section{DISCUSSÃO}

A Doença de Ménière se apresenta ainda nos dias de hoje com uma etiopatogenia a esclarecer. O quadro clínico inicial de edema facial apresentado pelo paciente e que inaugurou a sintomatologia do paciente é, sem dúvida, o ponto chave para a descoberta da etiologia.

Entretanto, diversas são as causas de edema facial em crianças. Entre elas podemos citar a erisipela, quadros alérgicos, rinosinusite complicada e síndromes renais como GNDA, sindrome nefrótica e tantos outros.

A suposição inicial de uma quadro de IRA ou síndrome nefrótica foi descartada, e uma avaliação cardiológica também não revelou qualquer patologia que justificasse o edema facial. Um possível "gatilho" alérgico poderia ser aventado como a causa deste edema e justificaria também a evolução para o Ménière. Entretanto, a real etiologia não pode ser comprovada, caindo naqueles $50 \%$ dos casos em que o diagnóstico etiológico não consegue ser determinado.

Outro fator que chama a atenção neste caso é a faixa etária apresentada pelo paciente, uma vez que as faixas etárias mais acometidas de Ménière variam entre a terceira e quinta décadas, sendo de ocorrência rara em crianças e adolescentes.

O tratamento clínico promoveu uma melhora sensivel no quadro clínico com o término dos episódios de crises que estavam se tornando mais freqüentes, demonstrando que o uso da vitamina $\mathrm{B} 6$ associado ao dimenidrinato junto da cinarizina promoveu a retirada da fase aguda e que o uso isolado da cinarizina manteve o paciente com o quadro estável.

\section{COMENTÁRIOS FINAIS}

A adolescência não é um período da vida de ocorrência comum da Doença de Ménière e as alterações congênitas do ouvido interno sempre devem ser aventadas nestas ocasiões, sendo um diagnóstico diferencial importante que pode ser descartado com a solicitação de TC ou de ressonância nuclear magnética.

Para se realizar um diagnóstico de Doença de Ménière, um grau de suspeição alto deve sempre estar presente pois só a associação das diversas sintomatologias apresentadas pela doença, junto a uma bateria de exames complementares, nos permite o diagnóstico da doença, e exames específicos, como o teste do glicerol, são imprescindíveis para a conclusão diagnóstica. 


\section{REFERÊNCIAS BIBLIOGRÁFICAS}

1. Akagi H, Yuen K, Maeda Y, Fukushima K, Orita Y; Kataoka Y Ogawa T. Ménière's disease in childhood. Int Japanese Pediat Otorhinolaryngol 2001; 61:259-64.

2. Bento R, Miniti A, Marone SA. Tratado de Otologia. 1a edição. São Paulo: Editora Universidade de São Paulo; 1998:387-9.

3. Hungria H. Otorrinolaringologia. $5^{\underline{a}}$ edição. Rio de Janeiro: Guanabara Koogan; 1984:429-44.

4. Ikezono T, Tomiyama S, Pawaikar R, Jiumouchi K, Suzuki Y. Passive transfer of experimental autoimmune labirinthitis. Audiol Neurootol 2000; 5:292-9.

5. Marks S, Arenberg KI, Hoffer ME. Round-window-mikrokatheter assistiert mikrodosierung von gentamycin: Alternative in der behandlung des tinnitus bei paciente mit morbus Ménière. LaryngoRhino-Otol 2000; 79:327-31.
6. Mizucoshi K, Shojaku H, Aso S, Asai M, Watanabe Y. Ménière's desease and delayed endolynphatic hydrops in children. Acta Otolaryngol Suppl 2001; 545:6-9.

7. McNaboe E.J, kerr A. History is the key in the diagnosis of vertigo. The Practitioner 2000; 244:648-53.

8. Rauch SD, Zurckowski D, Block KJ. Anti-Heat Shok Protein 70 antibodies in Ménières Disease. Laringoscope 1999; 110:151621.

9. Rivas J, Guzman J.E. Combined Vestibular neurectomy and endolynphatic sac shunt via the retrosigmoid aproach in the treatment of Ménière's Disease. Nose \& Troat Journal 2001; 79 (8):571-5.

10. Silverstein H, Norell H. Retrolarinthine Vestibular Neurectomy. Otoryngol Head Neck Surg 1982; 90:778-2.

11. Tirzaman O, Facer G.W, Fabry D.A, Beatty C.W. Use of methotrexate for autoimmune hearing loss. Ann Otol Rinol Laryngol 2000; 109:710-4. 